VII JORNADAS DE DIFUSIÓN DE LA INVESTIGACIÓN Y EXTENSIÓN - FCV-UNL

RESUMEN EXTENDIDO

\title{
DERMATITIS ULCERATIVA EN RATONES BALB/c Cmedc: REPORTE DE 3 CASOS
}

\author{
Sacco SC ${ }^{1}$, Belotti EM ${ }^{1}$, Pereyra EAL ${ }^{1}$, Sánchez Córdoba ID ${ }^{1}$, Neme $L^{1}$, \\ Rebelindo $\mathrm{E}^{1}$, Ortega $\mathrm{HH}^{1}$, Salvetti $\mathrm{NR}^{1}$.
}

${ }^{1}$ Centro de Medicina Comparada (CMC), Instituto de Ciencias Veterinarias del Litoral (ICiVet-Litoral), Universidad Nacional del Litoral (UNL) / Consejo Nacional de Investigaciones Científicas y Técnicas (CONICET). Esperanza, Santa Fe, Argentina.

* Correspondencia: Sacco S. E-mail: ssacco@fcv.unl.edu.ar

Editado por: R. Sobrero, V. Matiller, C. Baravalle

ULCERATIVE DERMATITIS IN BALBC/CMEDC MICE: REPORT OF 3 CASES.

SUMMARY.

Ulcerative dermatitis (UD) is a common and spontaneous condition in mice. The disease is characterized by a pruritic skin lesion, pain and a progressive evolution that often results in ulcerations. Sex, environmental conditions, dietary variation, chronic inflammation, barbering and follicular dystrophy are some predisposing factors for the clinical disease development. The aim of this study was report 3 cases of UD in BALBc/Cmedc mice from Center for Comparative Medicine, gross and histopathological lesions were described, and a review about relevance of UD in laboratory mice was made. These cases were characterized by dermatitis, ulcerative and proliferative, chronic, moderate, with neutrophils, hemorrhage and a serocellular crust. Although initial lesions may be mild, lesions in UD typically are unresponsive to treatment and euthanasia is often warranted in severe cases. This is the reason why UD is an important clinical issue that often affects biomedical research by causing problems in mice health and premature removal of animal from laboratory studies.

Palabras clave: Dermatitis ulcerativa; ratón; histopatología

Keywords: Ulcerative dermatitis; mouse; histopathology

La dermatitis ulcerativa (DU) en ratones de laboratorio se caracteriza por una dermatitis pruriginosa que resulta en ulceración dérmica, necrosis y fibrosis. Afecta a animales jóvenes y de edad avanzada, de las cepas B6, $\mathrm{BALB} / \mathrm{C}, \mathrm{C} 3 \mathrm{H} / \mathrm{He}$ y a ratones genéticamente modificados. La prevalencia varía entre 4 a $21 \%$ y puede resultar del aseo excesivo que provoca la caída del pelo (en inglés, barbering) en animales que se alojan en grupos o de traumas. En ratones B6, es un síndrome idiopático y la patogenia se ha asociado a una reacción de hipersensibilidad (Kastenmayer et al., 2006). Además, se han descripto numerosos factores predisponentes que aparentemente juegan un rol en el desarrollo de la DU. Entre los predisponente más relevantes encontramos: las condiciones ambientales, la dieta, la edad al destete, la presencia de zonas de 
alopecia (tricotilomania), el sexo (las hembras están más predispuestas), la displasia folicular, la deficiencia en el metabolismo de la vitamina $\mathrm{A}$, el dolor oronasal y la inflamación crónica. La ulceración puede sanar con fibrosis y retracción de la piel o progresar a una infección bacteriana secundaria. La DU puede presentarse en asociación con Staphylococcus aureus y S. xylosus. La patogénesis en estos casos implica una excoriación superficial de la piel y la colonización por parte de la bacteria, y la producción de proteínas biológicamente activas (hemolisinas, nucleasas, proteasas, lipasas, hialuronidasas, colagenasas $y$ exotoxinas) que conducen al desarrollo de una dermatitis necrótica progresiva. Las lesiones se presentan focalmente como pequeñas o extensas úlceras crónicas, a menudo en cabeza y cuello, pero también en tronco y base de la cola (Barthold et al., 2016).

El objetivo de este trabajo es reportar dermatitis ulcerativa en 3 ratones BALB/c Cmedc del Centro de Medicina Comparada (CMC), describir las lesiones macroscópicas y microscópicas de esta patología y hacer una revisión de la importancia de la enfermedad en ratones de laboratorio.

El presente trabajo se llevó adelante siguiendo procedimientos basados en guías internacionales de cuidado y uso de animales de laboratorio, y aprobadas por el Comité de Ética y Seguridad de la Facultad de Ciencias Veterinarias de la Universidad Nacional del Litoral (FCV-UNL). Durante el control veterinario de rutina a los animales de producción del CMC se detectaron 3 casos de lesiones dérmicas ulcerativas en ratones BALB/c Cmedc, 2 machos (11 y 13 meses) y 1 hembra (12 meses). Clínicamente presentaban pérdida de condición corporal, prurito y pelo hirsuto. Se realizó la eutanasia y necropsia completa, se tomaron muestras de las lesiones dérmicas en formol bufferado al $10 \%$. Las muestras se procesaron en el área de histopatología del $\mathrm{CMC}$ mediante la técnica de inclusión en parafina, cortes seriados de 4 micras de espesor con micrótomo (Leica RM 2245), coloración con Hematoxilina y Eosina (Biopur) y la posterior evaluación microscópica.

Macroscópicamente, las lesiones observadas en los animales se ubicaron en la cabeza en los tres animales, en la piel de la base de la oreja y pabellón auricular en un caso, párpado y región periocular en los otros dos ratones. Las lesiones se presentaron cómo áreas de necrosis con ulceración y exudado supurativo, focalmente extensas con bordes hemorrágicos $y$ costras. Microscópicamente, en los tres animales se evidenció dermatitis proliferativa necrótica, neutrofílica, difusa, severa. Marcada hiperplasia difusa de la epidermis afectando al estrato granuloso (hipergranulosis), espinoso (acantosis) e hiperqueratosis laminar. Multifocalmente, se observó necrosis y ulceración de la epidermis y la presencia de un material eosinófilo homogéneo (exudado seroso) mezclado con abundantes neutrófilos, muchos degenerados, restos celulares y de queratina adheridos superficialmente a la epidermis y a veces desprendido (costra). La dermis presentó marcada hiperemia y se encuentra expandida por infiltrados principalmente de neutrófilos entremezclados con una menor cantidad de linfocitos, macrófagos, eosinófilos, mastocitos y un material eosinófilo homogéneo (exudado seroso).

El prurito, el dolor y la predisposición genética han sido implicados como iniciadores de la enfermedad, y la alopecia y el eritema focal o multifocal se han informado como signos tempranos de la misma (Hampton et al., 2012). En los 3 casos descriptos en el presente trabajo los signos clínicos, las lesiones macroscópicas y microscópicas observadas fueron compatibles con DU. Debido a que no se remitieron muestras para microbiología, la asociación del proceso con estafilococos no puede afirmarse o descartarse. La presencia de úlceras dérmicas que ocasionan prurito $y$ dolor afectan el bienestar y la salud animal, y los posibles efectos de confusión que genera esta enfermedad cuando se presenta en animales que se encuentran en ensayos con frecuencia determina la eutanasia de los animales afectados. Por ello, la enfermedad tiene un importante impacto en ratones de laboratorio y su conocimiento y diagnóstico precoz es fundamental para asegurar el bienestar, cuidado, uso racional y ético de los animales de laboratorio, además de asegurar la calidad de los resultados obtenidos en protocolos de investigación que involucren a esta especie utilizada.

\section{Bibliografía}

Barthold SW, Griffey SM, Percy DH. 2016. Pathology of laboratory rodents and rabbits. 4 edition. Ed. WileyBlackwell, lowa. 144-145 pp.

Hampton AL, Hish GA, Aslam MN, Rothman ED, Bergin IL, Patterson KA, Naik M, Paruchuri T, Varani J, Rush HG. 2012. Progression of ulcerative dermatitis lesions in C57BL/6Crl mice and the development of a scoring system for dermatitis lesions. J Am Assoc Lab Anim Sci. 5: 586-93.

Kastenmayer RJ, Fain MA, Perdue KA. 2006. A retrospective study of idiopathic ulcerative dermatitis in mice with a C57BL/6 Background. J Am Assoc Lab Anim Sci. 45: 8-12. 